\title{
Altered ventral neck muscle deformation for individuals with whiplash associated disorder compared to healthy controls - A case-control ultrasound study
}

Gunnel Peterson, Asa Dedering, Erika Andersson, David Nilsson, Johan Trygg, Michael

Peolsson, Thorne Wallman and Anneli Peolsson

\section{Linköping University Post Print}

\section{Tweet}

N.B.: When citing this work, cite the original article.

Original Publication:

Gunnel Peterson, Asa Dedering, Erika Andersson, David Nilsson, Johan Trygg, Michael Peolsson, Thorne Wallman and Anneli Peolsson, Altered ventral neck muscle deformation for individuals with whiplash associated disorder compared to healthy controls - A case-control ultrasound study, 2015, Manual Therapy, (20), 2, 319-327.

http://dx.doi.org/10.1016/j.math.2014.10.006

Copyright: Elsevier

http://www.elsevier.com/

Postprint available at: Linköping University Electronic Press

http://urn.kb.se/resolve?urn=urn:nbn:se:liu:diva-115920 
Altered ventral neck muscle deformation for individuals with Whiplash Associated Disorder compared to Healthy Controls; a case-control Ultrasound study

Gunnel Peterson, PT, MSc, ${ }^{1,2}$, Åsa Dedering,PT PhD ${ }^{3}$, Erika Andersson, $\mathrm{MSc}^{2}$, David Nilsson $\mathrm{Phd}^{4}$, Johan Trygg PhD, Prof ${ }^{4}$, Michael Peolsson CE, Phd ${ }^{4}$, Thorne Wallman, MD, PhD ${ }^{1,5}$, Anneli Peolsson, PT, PhD, Assoc. Prof ${ }^{2}$

${ }^{1}$ Centre for Clinical Research Sörmland, Uppsala University, Eskilstuna, Sweden

${ }^{2}$ Department of Medical and Health Sciences, Division of Physiotherapy, Faculty of Health Sciences, Linköping University, Linköping, Sweden

${ }^{3}$ Department of Neurobiology, Care Sciences and Society, Division of

Physiotherapy, Karolinska Institutet and Department of Physical Therapy, Karolinska University Hospital, Sweden

${ }^{4}$ Department of Chemistry, Computational Life Science Cluster, Umeå University, Sweden ${ }^{5}$ Uppsala University, Public Health \& Caring Sciences, Family Medicine \& Preventive Medicine Section, Uppsala, Sweden

Address correspondence to Gunnel Peterson, Division of Physiotherapy, Department of Medical and Health Sciences, Linköpings University, SE-581 83 Sweden. E-mail: gunnel.peterson@liu.se

$\underline{\text { Keywords }}$

Whiplash injury; ultrasonography; neck muscles 
Some long-lasting symptoms associated with whiplash-associated disorders (WAD) (Berglund et al., 2001; Kongsted et al., 2007; Carroll et al., 2009) may be due to impaired neck muscle function with altered motor control patterns (Jull et al., 2004; Woodhouse and Vasseljen, 2008; O'Leary et al., 2011). Changed activation of the deep muscle layer (Falla et al., 2004a), which is thought to stabilize the spine (Panjabi, 1992; Mayoux-Benhamou et al., 1994), might increase neck disability. Magnetic resonance imaging can non-invasively distinguish between the deep cervical flexors, longus capitis (Lcap), and longus colli (Lco) (Cagnie et al., 2008; Cagnie et al., 2010; Elliott et al., 2010); but cannot be used to investigate muscles during movement. Surface electromyography (EMG) has demonstrated increased activity in the sternocleidomastoid (SCM) muscle (Falla et al., 2004b; Jull et al., 2004) and invasive EMG studies (electrode contacts inserted through the nose) reported a delayed activation of the deep cervical flexors in chronic neck pain (Falla et al. 2004a; Falla et al. 2004c). Nevertheless, EMG investigations run a risk of cross-talk between muscles, and cannot distinguish between the Lcap and Lco. Still image ultrasonography can measure the thickness of deep ventral neck muscles (Cagnie et al., 2009; Javanshir et al., 2011), but it provides no information about neck muscle function during real-time motion. With ultrasound, the muscle of interest may be influenced by neighboring tissues or external pressure from the probe. Nevertheless; the ability to investigate deep and superficial muscle functions together, during real time activations (Lopata et al., 2010; Peolsson et al., 2010 Peolsson et al., 2014) makes this method interesting. Speckle tracking is a post-process method for analyzing ultrasound images; it facilitates measuring muscle deformations (elongations and shortenings) and deformation rates, and this information has improved our understanding of real time (Lopata et al., 2010) mechanical neck muscle function in different muscle layers (Peolsson et al., 2012). To our knowledge, this approach has not been previously applied in individuals with chronic WAD. The objective of the present study was 
to compare deformations and deformation rates in the SCM, Lcap, and Lco in individuals with WAD vs. control subjects, during repetitive arm elevations. In addition, we aimed to determine if the interplay of the three muscles differed between the WAD and control groups. We hypothesized that deformation and deformation rates would be increased in the SCM and decreased in the Lcap and Lco for individuals with chronic WAD compared to healthy controls.

\section{METHODS}

\section{$\underline{\text { Participants }}$}

Twenty-six individuals, 20 women and 6 men (mean age 37 years, SD; 10.6) with persistent neck pain after a whiplash injury and 26 controls, matched for age and sex, participated in the study (Table 1). As no previous study has compared deformation and deformation rate between WAD and controls, the sample size was arbitrary.

Individuals with WAD were consecutively recruited for ultrasound investigation from a larger, ongoing, randomized controlled trial (Peolsson et al., 2013).

For study eligibility, individuals had to report neck pain in the right side of the neck, righthandedness, and fluency in Swedish. Study inclusion criteria were positive manual examination findings that corresponded to WAD grade II (neck pain and musculoskeletal signs) or III (neck pain plus neurological signs) (Spitzer et al., 1995); persistent neck pain rated greater than $20 \mathrm{~mm}$ on a visual analogue scale (VAS), and/or neck disability greater than 20\% (MacDermid et al., 2009), measured with the neck disability index (NDI); aged 18 - 63 years; and ongoing symptoms associated with a whiplash injury that started six months to three years prior to study entry. 
Exclusion criteria were signs of traumatic brain injury at the time of whiplash injury; known or suspected serious pathology; previous fracture or luxation in the cervical spine;

contraindication to exercise; neuromuscular diseases; rheumatologic disease; previous serious neck pain that warranted more than 1 month of sick leave in the year prior to their whiplash injury; severe mental illness; or current alcohol or drug abuse.

The healthy controls were recruited from university staff, hospital staff, and acquaintances. Exclusion criteria were current or past neck problems; trauma to the neck or head including whiplash injury; neck or low back pain; rheumatologic or neurologic disease; or generalized myalgia. The study was approved by the Regional Ethics Review Board and was conducted according to the Declaration of Helsinki. Written informed consent was obtained from all participants.

\section{Ultrasound measurements}

The ventral neck muscles were recorded with a B-mode, 2-D ultrasound Vivid-I scanner (GE Healthcare, Horten, Norway). The ultrasound was equipped with a $12 \mathrm{MHz}$ linear transducer (38 mm) with high frame rate (235 frames/s). Ultrasound measurements of the SCM, Lcap, and Lco were recorded during repetitive arm elevations. Each test included 10 arm elevations, and ultrasound images ("video" sequences) were acquired during the first and tenth arm elevations. The ultrasound probe was positioned at the $\mathrm{C} 4$ level on the right side of the neck (Fig. 1a). The segmental level was verified with a transverse ultrasound projection of the bifurcation of the carotid artery, commonly observed at the $\mathrm{C} 4$ level. The transducer was then rotated to a longitudinal position, which allowed optimal imaging of the SCM, Lcap, and Lco muscles. All ultrasound measurements were acquired in this longitudinal position (Fig. 1b). 


\section{Speckle tracking}

Ultrasound of muscle results in reflection of sound waves, which serve as acoustic markers because they form a unique speckle pattern. Briefly, a region of interest (ROI) was manually placed in the first frame of the video sequence of each muscle. Tracking the unique speckle pattern of the respective ROI was based on an algorithm developed by Kanade-Lukas-Tomasi (KLT) (Lucas and Kanade, 1981; Tomasi and Kanade, 1991), which was further enhanced (Farron et al., 2009). Accordingly, when the muscle speckle pattern changes length, the tracked ROI also changes in length, and the unique pattern can be followed frame by frame throughout the ultrasound images. The ROI comprises a large number of points placed equidistant between the two endpoints. The frame to frame displacement can then obtained with a least squares fit, assuming a linear strain model. The displacement of all points within the ROI were summed, to obtain a cumulative sum from all frames in the movie which provided quantitative information of muscle behavior during the arm elevation.

Muscle Deformation was defined as a change in ROI length (elongation or shortening), calculated as the percentage change (\% deformation) from the original length; provided information about local tissue dynamics. The Muscle Deformation Rate was defined as the rate of the change in deformation, expressed as the amount of deformation per time unit (\% deformation/s). Three ROIs (each ROI was $10 \times 3.3 \mathrm{~mm}$ ) were positioned longitudinally in each of the muscles (i.e., oriented longitudinal to the muscle fibers); together, the three ROIs covered $30 \mathrm{~mm}$ of the unique speckle pattern in each muscle (Fig. 2). The magnitude of muscle deformation measured with speckle tracking was positively related to other measurements used to investigate muscle deformation (force measurements and progressive electrical stimulation) (Lopata et al., 2010). The reliability of the speckle tracking analysis method was shown to have excellent test-retest reliability (two-way random absolute 
agreement single measure intraclass correlation coefficient [ICC)] 0.71-0.97) (Peolsson et al. in press).

\section{$\underline{\text { Test procedure }}$}

Two experienced physiotherapists were present during the test, one performed the ultrasound examination and the other assisted the ultrasound examiner. The experiment was designed to resemble activities that might increase neck pain in individuals with poor functional recovery after whiplash injury; for example, performing a job with repetitive arm lifting (Sullivan et al., 2010). To standardize the test; we included only right-handed individuals with dominant right-sided neck pain (Fig. 1b). Before the measurements began, the individual practiced the test with the left arm.

\section{Other measurements}

Pain

The average pain intensity experienced over the prior week was assessed with a visual analogue scale (VAS 0-100 mm scale, $0=$ no pain, $100=$ worst imaginable pain) (Carlsson, 1983).

Neck disability

Disability was measured with the neck disability index (NDI). The NDI consists of 10 items, expressed as a percentage (total possible score 100\%), with higher scores indicating greater disability (MacDermid et al., 2009).

\section{Physical activity}

Subjects answered questions about daily life activities (walking, cycling to work etc.) and exercise beyond daily life activities performed over the last 12 months. The answers were 
combined to calculate the activity index $(1=$ inactivity, $2=$ low activity, $3=$ moderate activity, $4=$ high activity) (Kallings et al., 2008).

\section{Neck muscle fatigue}

The participants rated fatigue in the neck muscles before and after the ultrasound test on a Borg CR-10 scale $(0=$ no fatigue, $10=$ extremely strong fatigue $)$, (Borg, 1990).

\section{Data analyses}

Ultrasonography data were post-processed with speckle tracking methodology implemented with a program designed in-house for Matlab (Matlab., 2013). The KLT tracking algorithm was part of the Computer Vision toolbox of Matlab. To evaluate muscle deformations for the first and tenth arm elevations, the areas on the deformation curves were calculated (Fig. 3). Deformation rate results are presented as the root mean square (RMS), which gives information about the local tissue velocity of deformation. Therefore, the deformation and deformation rate measure the mechanical function of the muscle.

The ultrasound video images were coded during the post-process analyses. Thus, the analyzer (the PT with three years of experience with speckle-tracking analyses) was blinded to the group affiliation

\section{$\underline{\text { Statistical analyses }}$}

All data analyses were performed with SPSS statistical software, version 20. Demographic variables were compared between groups using the two-tailed unpaired Students t-test and the $\mathrm{Chi}^{2}$ test. Between-group differences in physical activity levels and neck muscle fatigue were analyzed with the Mann Whitney U test. 
Deformation measurements were skewed; therefore, non-parametric tests were applied. The deformation rate data were normally distributed and parametric tests were applied. The correlations of deformations among the SCM, Lcap, and Lco during the first and tenth arm elevations were evaluated with Spearman's rho test (for deformation) and Pearson's correlation (for deformation rate). Linear regression models were applied to investigate the relationships of the deformations and the deformation rate among the three muscles (SCM/Lcap, SCM/Lco, Lcap/Lco) for individuals in both groups (control and WAD). One outlier (WAD) in the deformation rate and one outlier from each group (WAD/Control) in the deformation had some impact on the results for correlation and linear regression analysis; therefore these where excluded from the analysis.

A mixed design analysis of variance (ANOVA) with Bonferroni correction was used to evaluate the change in deformation rate. The groups (control and WAD) were the betweensubjects variable, the three muscles (SCM, Lcap, and Lco) were the within-subject variables, and the analysis was adjusted for the duration of each arm elevation. The deformation values were positive-skewed, and the assumptions of variance were violated (Levene's test $\mathrm{p}<$ 0.05). Thus, the data were analyzed with the non-parametric test, Friedman ANOVA, and the Mann Whitney U test.

We used the Wilcoxon signed-rank test for paired two group analyses of differences in the deformation between the first and tenth arm elevations and the paired sampled T-test for deformation rates. P-values $\leq 0.05$ were considered significant. Effect sizes (ES) were calculated for the deformations $E S=\frac{Z}{\sqrt{N}}$ (non-parametric; z-score divided by the square root of the number of total observations $[\mathrm{N}]$ ) and deformation rates $E S=\sqrt{\frac{t 2}{t 2+d f}}$ (parametric; the square root of the $\mathrm{t}$-score $\mathrm{x} t$-score $\left(\mathrm{t}^{2}\right)$ divided by $\mathrm{t}^{2}+$ degree of freedom [df]) 


\section{$\underline{\text { RESULTS }}$}

\section{Deformation}

Comparisons between the WAD and control groups

When evaluating deformation, the only significantly different finding was that the SCM was less elongated in individuals with WAD compared with controls during the first arm elevation (Table 2).

\section{Comparison between the first and tenth arm elevations}

In controls, all three ventral neck muscles showed significantly less deformation (total area) during the tenth arm elevation compared to the first elevation and the muscles were activated with less shortening (ES: 0.42 to 0.70 ). In individuals with WAD, only the SCM showed less deformation in the tenth than in the first elevation, and it was also activated with less shortening (ES: 0.68) (Table 2).

Deformations of SCM, Lcap, and Lco during the first and tenth arm elevations

In both groups, the deformations observed in the three muscles were significantly different during the arm elevations. The total area was lower in the SCM than the Lcap and Lco.

\section{Correlation}

When control subjects performed arm elevations, the deformations in the first elevation significantly correlated between SCM/Lcap $(r=0.50)$ and SCM/Lco $(r=0.59)$; in addition, the strength of correlations increased during the tenth arm elevation for all three muscle pairs $(\mathrm{r}=0.51$ to 0.80$)$. For individuals with WAD, there was no correlation among muscles during the first arm elevation, while there were correlation between SCM/Lcap $(r=0.40)$ and Lcap/Lco $(r=0.73)$ during the tenth elevation during the tenth elevation (Table 3$)$. 


\section{Linear relationship}

For controls, there was a positive linear relationship between all muscle pairs (SCM/Lco, SCM/Lcap, and Lcap/Lco ) that increased from the first to the tenth arm elevation. In contrast, individuals with WAD, only showed a positive linear relationship for Lcap/Lco during the tenth arm elevation (Fig. 4 a-f).

\section{Deformation rate}

Differences in deformation rates between and within groups (control and WAD)

A significant main effect between groups was observed in the deformation rate during the tenth arm elevation, $\mathrm{F}(1,48)=5.3(\mathrm{p}<0.01)$, where individuals with WAD showed an increased Lco deformation rate compared to controls $F(1,48)=4.6$. In addition, both groups showed a significant interaction effect between muscles, the SCM showed a lower rate than Lcap and Lco in the tenth arm elevations, $F(1,48)=7.2(\mathrm{p}<0.01)$. No significant betweengroup effect was observed during the first arm elevation, $F(1,46)=0.81$. For controls, the deformation rates decreased during the tenth arm elevation compared to first in all three muscles. For individuals with $\mathrm{WAD}$, the deformation rates only decreased in the tenth arm elevation compared with the first for the SCM (Table 4).

\section{Correlation}

For controls, during both the first and tenth arm elevations, the deformation rates were significantly correlated among all three muscles $(r=0.51$ to 0.84$)$. For individuals with WAD, the first arm elevations, showed significant correlations among all three muscles $(r=$ 0.55 to 0.66$)$; while, in the tenth arm elevations only the Lcap and Lco were correlated ( $\mathrm{r}=$ 0.49) (Table 3). 


\section{Linear relationship}

For controls, the positive linear relationship for SCM/Lcap increased from the first to tenth arm elevations. The relationships between SCM/Lco and Lcap/Lco were the same for both arm elevations. Individuals with WAD, showed a decreased linear relationship from the first to tenth arm elevations for all three muscle pairs (Fig 5 a-f).

\section{$\underline{\text { Neck muscle fatigue }}$}

The WAD group showed significantly higher fatigue (median 4.0, IQR: 2.7 to 5.2) compared to controls (median 0.0, IQR: 0 to 0$)(\mathrm{p}<0.001)$ before the first arm elevation. After the tenth arm elevation the fatigue did not changed for either group (WAD [median 4.0, IQR: 2.7 to 6.0], controls [median 0.0, IQR: 0 to 0.1$]$ ).

\section{$\underline{\text { DISCUSSION }}$}

We found only a few significant differences between individuals with WAD and healthy controls in the deformations and deformation rates for the SCM, Lcap, and Lco muscles. Our results did reveal that the interplay between pairs of muscles, SCM/Lco, SCM/Lcap, and Lcap/Lco, was altered in the WAD group compared with the control group. Based on earlier studies, we hypothesized that SCM activity would increase and activity in the deep neck flexors would decrease during arm movements for individuals with WAD compared to controls (Falla et al., 2004b; Falla et al., 2004c; Jull et al., 2004). However, our results did not confirm the hypothesis of group differences between healthy controls and individuals with WAD. An explanation could be that highly individual muscle patterns, made it difficult to detect significant differences between groups, due to large standard deviations. Another explanation for the lack of differences in group level findings could be that ultrasound data 
from the present study were not directly comparable to EMG data from earlier studies (Falla et al., 2004a; Falla et al., 2004b; Jull et al., 2004). EMGs measure muscle action potentials, which reflect the chemical-electrical changes in muscles and nerves; in contrast, real-time ultrasound measure deformation. Deformation was calculated from a series of measurements (235 measurments/s) taken during arm elevation (average elevation time $2.5 \mathrm{~s}$ ), that produced a curve of muscle elongation and shortening (Fig. 3). On that curve, a greater area represented greater deformation.

In controls, we observed an individual muscle pattern of low deformation and deformation rates or high deformation and deformation rates in SCM/Lco, SCM/Lcap and Lcap/Lco. In individuals with WAD, this correlation was altered, which may indicate diminished cooperation between muscles after ten arm elevations. The linear relationship between superficial and deep neck muscles (SCM/Lco and SCM/ Lcap) was increased in the control group (moderate to strong) compared to the diminished or weakened relationship for the WAD group (Fig 4 and 5 a-d). The linear relationship between Lcap/Lco deformations increased from weak to moderate from the first to tenth arm elevation in both the WAD and control groups (Fig 4 e,f). However, the relationship between the Lcap/Lco deformation rates decreased from moderate to weak from the first to tenth arm elevation in the WAD group; whereas, controls showed a moderate relationship during both the first and tenth arm elevation (Fig 5 e,f). Thus, although the groups showed similar relationships in deformation in Lcap/Lco, the relationship between the deep muscle deformation rates weakened with time for the WAD group. In light of this finding and reports from other studies (Hodges et al., 2013; Hug et al., 2013), it appears that comparing the individual relationships among muscles is informative. In addition, ultrasound speckle tracking can be a complementary analysis to neck muscle activations detected by EMG (Falla et al., 2004a). 
The WAD group reported fatigue even before the first arm elevation, and the relationships between several muscles had weakened after ten arm elevations. The deformation rate included both acceleration and deceleration rates (RMS). Thus, both high deformation rates and no correlations between muscles (e.g., when a car accelerates or brakes all the time) may indicate an ineffective muscle activation pattern that could result from or cause fatigue and/or pain.

\section{$\underline{\text { Limitations and further recommendations }}$}

Ultrasound with post-process speckle tracking provides a non-invasive method to investigate muscle deformation in real time (Lopata et al., 2010; Peolsson et al., 2012). However, although the method was sucessfully validated against force measurements (Lopata et al., 2010), more studies are required to validate this method. The probe pressure and possible small neck movements during the test could have influenced the results. Also, the lack of significant anatomical landmarks could have limited the precision of probe placement; however, the bifurcation of the carotid artery (commonly at the C4 level) (Civielek et al. 2007) and the vertebral column were used as reference points. Another potential limitation of the study was that the ROI was selected manually for each muscle of interest. Thus, like in EMG investigations, the ROI may not adequately represent the whole muscle. Real time ultrasound investigation causes some uncertainty if the probe is placed in the same area in all study participants. However, we studied three ROIs that covered $30 \mathrm{~mm}$ of the muscle (probe size $38 \mathrm{~mm}$ ); this larger area would minimize the differences between inidviduals and increase measurment accuracy. In the WAD group, eight (of 26) participants had neurological symptoms (grade III); which could have affected the results, due to potential changes in dorsal nerves and neck muscle interactions. 


\section{CONCLUSION}

This study showed only a few group differences in the deformations and the deformation rates in the SCM, Lcap, and Lco muscles when comparing individuals with WAD and healthy controls. This study demonstrated that, in the control group, the deformations and deformation rates in one muscle correlated with deformations and deformation rates in other neck muscles. This interplay between muscles was altered in individuals with WAD. Further studies are required to develop a mathematical model that can determine when the neck muscle activation pattern becomes abnormal.

\section{$\underline{\text { REFERENCES }}$}

Berglund A, Alfredsson L, Jensen I, Cassidy JD, Nygren A. The association between exposure to a rear-end collision and future health complaints. J Clin Epidemiol 2001;54:8516. http://dx.doi.org/ S0895-4356(00)00369-3

Borg G. Psychophysical scaling with applications in physical work and the perception of exertion. Scand J Work Environ Health 1990;16:55-8.

Cagnie B, Derese E, Vandamme L, Verstraete K, Cambier D, Danneels L. Validity and reliability of ultrasonography for the longus colli in asymptomatic subjects. Man ther 2009;14:421-6. http://dx.doi.org/ 10.1016/j.math.2008.07.007

Cagnie B, Dickx N, Peeters I, Tuytens J, Achten E, Cambier D, et al. The use of functional MRI to evaluate cervical flexor activity during different cervical flexion exercises. J Appl Physiol 2008;104:230-5. http://dx.doi.org/ 10.1152/japplphysiol.00918.2007

Cagnie B, Dolphens M, Peeters I, Achten E, Cambier D, Danneels L. Use of muscle functional magnetic resonance imaging to compare cervical flexor activity between patients with whiplash-associated disorders and people who are healthy. Phys Ther 2010;90:115764.http://dx.doi.org/ 10.2522/ptj.20090351 
Carlsson AM. Assessment of chronic pain. I. Aspects of the reliability and validity of the visual analogue scale. Pain 1983;16:87-101.

Carroll LJ, Holm LW, Hogg-Johnson S, Cote P, Cassidy JD, Haldeman S, et al. Course and prognostic factors for neck pain in whiplash-associated disorders (WAD): results of the Bone and Joint Decade 2000-2010 Task Force on Neck Pain and Its Associated Disorders. J Manipulative Physiol Ther2009;32:S97-S107. http://dx.doi.org/ 10.1016/j.jmpt.2008.11.014 Civelek E, Kiris T, hepgul K, Canbolat A, Ersoy G, Cansever T. Anterolateral apporach to the cervical spine: major anatomical structures and landmarks. J Neurosurg Spine 2007;35:948-54 http://dx.doi.org/ 10.3171/SPI-07/12/669Elliott JM, O'Leary S, Sterling M, Hendrikz J, Pedler A, Jull G. Magnetic resonance imaging findings of fatty infiltrate in the cervical flexors in chronic whiplash. Spine 2010;35:948-54. http://dx.doi.org/ 10.1097/BRS.0b013e3181bb0e55

Falla D, Jull G, Hodges PW. Feedforward activity of the cervical flexor muscles during voluntary arm movements is delayed in chronic neck pain. Exp Brain Res 2004a;157:43-8. http://dx.doi.org/ 10.1007/s00221-003-1814-9

Falla D, Bilenkij G, Jull G. Patients with chronic neck pain demonstrate altered patterns of muscle activation during performance of a functional upper limb task. Spine . 2004b;29:1436-40. http://dx.doi.org/ 00007632-200407010-00011 [pii] Falla DL, Jull GA, Hodges PW. Patients with neck pain demonstrate reduced electromyographic activity of the deep cervical flexor muscles during performance of the craniocervical flexion test. Spine 2004c;29:2108-14. 
Hodges PW, Coppieters MW, MacDonald D, Cholewicki J. New insight into motor adaptation to pain revealed by a combination of modelling and empirical approaches. Eur $\mathbf{J}$ Pain 2013;17:1138-46. http://dx.doi.org/ 10.1002/j.1532-2149.2013.00286.x

Hug F, Hodges PW, Tucker KJ. Effect of pain location on spatial reorganisation of muscle activity. J Electromyogr Kinesiol 2013;23:1413-20. http://dx.doi.org/ 10.1016/j.jelekin.2013.08.014

Javanshir K, Rezasoltani A, Mohseni-Bandpei MA, Amiri M, Ortega-Santiago R, Fernandezde-Las-Penas C. Ultrasound assessment of bilateral longus colli muscles in subjects with chronic bilateral neck pain. Am J Phys Med Rehabil 2011;90:293-301. http://dx.doi.org/ 10.1097/PHM.0b013e31820173e5

Jull G, Kristjansson E, Dall'Alba P. Impairment in the cervical flexors: a comparison of whiplash and insidious onset neck pain patients. Man Ther 2004;9:89-94. http://dx.doi.org/ $10.1016 / \mathrm{s} 1356-689 x(03) 00086-9$

Kallings LV, Leijon M, Hellenius ML, Stahle A. Physical activity on prescription in primary health care: a follow-up of physical activity level and quality of life. Scand J Med Sci Sports 2008;18:154-61. http://dx.doi.org/ 10.1111/j.1600-0838.2007.00678.x

Kongsted A, Qerama E, Kasch H, Bendix T, Bach FW, Korsholm L, et al. Neck collar, "actas-usual" or active mobilization for whiplash injury? A randomized parallel-group trial. Spine 2007;32:618-26. http://dx.doi.org/ 10.1097/01.brs.0000257535.77691.bd

Lopata RG, van Dijk JP, Pillen S, Nillesen MM, Maas H, Thijssen JM, et al. Dynamic imaging of skeletal muscle contraction in three orthogonal directions. J Appl Physiol 2010;109:906-15. http://dx.doi.org/ 10.1152/japplphysiol.00092.2010 
Lucas BD, Kanade T. "An Iterative Image Registration Technique with an Application to Stereo Vision,"Proceedings of the 7th International Joint Conference on Artificial Intelligence 1981;674-679.

MacDermid JC, Walton DM, Avery S, Blanchard A, Etruw E, McAlpine C, et al. Measurement properties of the neck disability index: a systematic review. J Orthop Sports Phys Ther 2009;39:400-17. http://dx.doi.org/:10.2519/jospt.2009.2930

Matlab 2013a, The Mathworks Inc, Natick, MA, USA.

Mayoux-Benhamou MA, Revel M, Vallee C, Roudier R, Barbet JP, Bargy F. Longus colli has a postural function on cervical curvature. Surg Radiol Anat 1994;16:367-71. O'Leary S, Falla D, Jull G. The relationship between superficial muscle activity during the craniocervical flexion test and clinical features in patients with chronic neck pain. Man ther 2011,16:452-5. http://dx.doi.org/ 10.1016/j.math.2011.02.008

Panjabi MM. The stabilizing system of the spine. Part I. Function, dysfunction, adaptation, and enhancement. J Spinal Disord 1992;5:383-9.

Peolsson A, Landen Ludvigsson M, Overmeer T, Dedering A, Bernfort L, Johansson G, et al. Effects of neck-specific exercise with or without a behavioural approach in addition to prescribed physical activity for individuals with chronic whiplash-associated disorders: a prospective randomised study. BMC Musculoskelet Disord 2013;14:311. http://dx.doi.org/ $10.1186 / 1471-2474-14-311$

Peolsson A, Lofstedt T, Trygg J, Peolsson M. Ultrasound imaging with speckle tracking of cervical muscle deformation and deformation rate: Isometric contraction of patients after anterior cervical decompression and fusion for cervical disc disease and controls. Man ther 2012;17:519-25 http://dx.doi.org/ 10.1016/j.math.2012.05.005 
Peolsson A, Marstein E, McNamara T, Nolan D, Sjaaberg E, Peolsson M, et al. Does posture of the cervical spine influence dorsal neck muscle activity when lifting? Man ther 2014;19:32-6. http://dx.doi.org/ 10.1016/j.math.2013.06.003

Peolsson A, Peolsson M, Jull G, Lofstedt T, Trygg J, O’Leary S. Preliminary evaluation of dorsal muscle activity during resisted cervical extension in patients with longstanding pain and disability following anterior cervical decompression and fusion surgery. In press: Physiotherapy (2014) http://dx.doi.org/ 10.1016/j.physio.2014.04.010

Peolsson M, Lofstedt T, Vogt S, Stenlund H, Arndt A, Trygg J. Modelling human musculoskeletal functional movements using ultrasound imaging. BMC Med Imaging 2010;10:9. http://dx.doi.org/ 10.1186/1471-2342-10-9

Spitzer WO, Skovron ML, Salmi LR, Cassidy JD, Duranceau J, Suissa S, et al. Scientific monograph of the Quebec Task Force on Whiplash-Associated Disorders: redefining "whiplash" and its management. Spine 1995;20:1-73.

Sullivan MJ, Lariviere C, Simmonds M. Activity-related summation of pain and functional disability in patients with whiplash injuries. Pain 2010;151:440-6. http://dx.doi.org/ 10.1016/j.pain.2010.08.005

Tomasi C, Kanade T. Detection and Tracking of Point Features, Computer Science Department, Carnegie Mellon University, April, 1991.

Woodhouse A, Liljeback P, Vasseljen O. Reduced head steadiness in whiplash compared with non-traumatic neck pain. J Rehabil Med 2010;42:35-41. http://dx.doi.org/ $10.2340 / 16501977-0484$

Woodhouse A, Vasseljen O. Altered motor control patterns in whiplash and chronic neck pain. BMC Musculoskelet Disord 2008;9:90. http://dx.doi.org/ 10.1186/1471-2474-9-90 
Table 1. Characteristics of participants in the study

\begin{tabular}{|c|c|c|c|}
\hline & \multicolumn{3}{|c|}{ Healthy controls } \\
\hline & WAD $(\mathrm{N}=26)$ & $(\mathrm{N}=26)$ & $\mathrm{P}$ \\
\hline Gender, female (number and \%) & $20(77 \%)$ & $20(77 \%)$ & 1.0 \\
\hline WAD grade II/III (number) & $18 / 8$ & 0 & 0.001 \\
\hline Age (years; mean and SD) & $37(10.9)$ & $37(10.9)$ & 0.96 \\
\hline Injury duration $^{\mathrm{a}}$ (months, mean and SD) & $22(7.7)$ & 0 & $<0.001$ \\
\hline $\mathrm{BMI}^{\mathrm{b}}$ male (mean and SD) & $25(6.6)$ & $25(3.5)$ & 0.81 \\
\hline BMI female (mean and SD) & $25(5.4)$ & $22(2.4)$ & 0.01 \\
\hline Physical activity level ${ }^{\mathrm{c}}$ (median and range) & $2(2-3)$ & $4(3-4)$ & 0.001 \\
\hline Neck Disability Index ${ }^{\mathrm{d}}$ (mean and SD) & $34(13.4)$ & $1(1.6)$ & 0.001 \\
\hline Pain previous week ${ }^{\mathrm{e}}$ (VAS; mean and SD) & $50(18.8)$ & $1(1.0)$ & 0.001 \\
\hline
\end{tabular}

a) Months since whiplash injury, range 6 to 36 months.

b) BMI; Body Mass Index $\left(\mathrm{kg} / \mathrm{m}^{2}\right)$.

c) Physical activity level over the prior 12 months $(1=$ inactivity, $2=$ low activity, $3=$ moderate activity, $4=$ high activity)

d) Neck Disability Index Score (0-100\%) was based on 10 items; higher scores represented higher disability.

e) VAS; Visual analogue scale, average pain in the prior week, range 0-100 $\mathrm{mm}$, higher rating represented higher pain intensity. 
Table 2. Muscle deformations (\% change in length) during the first (1st) and the tenth (10th) arm elevation. Total area represents the sum of elongations and shortenings of the muscle, expressed as the median and interquartile range (IQR) for each group.

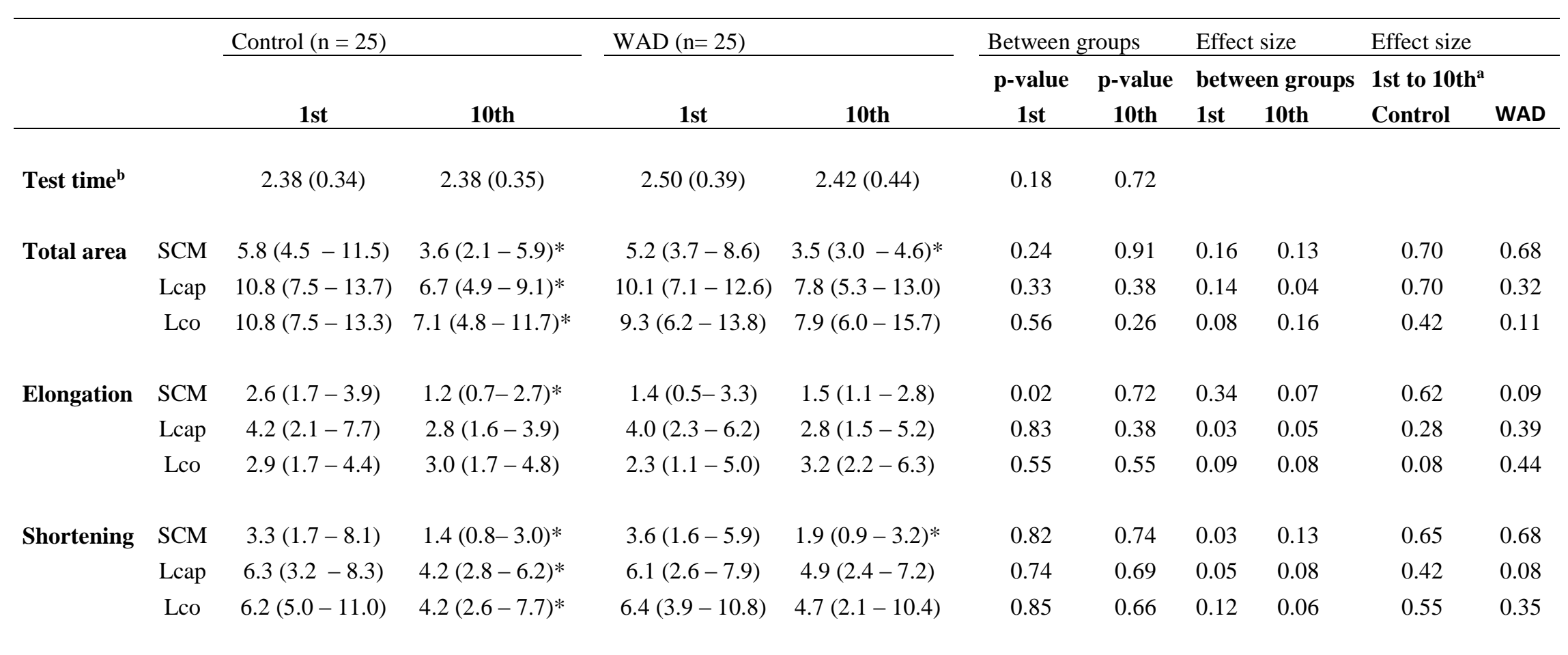

${ }^{\mathrm{a}}$ Effect size for the within group changes from the $1^{\text {st }}$ to $10^{\text {th }}$ arm elevation.

${ }^{\mathrm{b}}$ Test time in seconds for the 1 st and $10^{\text {th }}$ arm elevation, mean (SD).

*Significant differences $(\mathrm{p}<0.05)$ between the first and tenth arm elevations 
Table 3. Correlations between the sternocleidomastoid (SCM), longus capitis (Lcap), and longus colli (Lco) muscles in deformations and deformation rates during the first (1st) and tenth (10th) arm elevations for individuals with WAD and healthy controls.

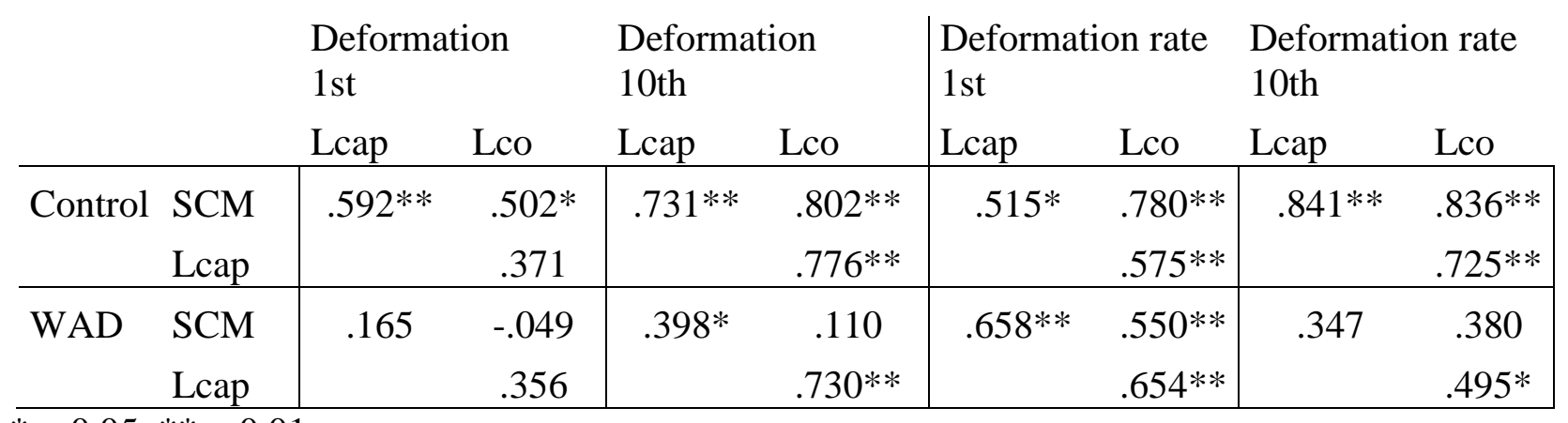


Table 4.

Deformation rate (\% deformation/s) in sternocleidomastoid (SCM), longus capitis (Lcap) and longus colli (Lco) during the first (1st) and tenth (10th) arm elevations, mean (SD).

\begin{tabular}{|c|c|c|c|c|c|c|c|c|c|c|}
\hline & \multicolumn{2}{|l|}{ Control } & \multicolumn{2}{|l|}{ WAD } & \multicolumn{2}{|c|}{ Between groups } & \multirow{2}{*}{\multicolumn{2}{|c|}{$\begin{array}{l}\text { Effect size } \\
\text { Between groups }\end{array}$}} & \multirow{2}{*}{\multicolumn{2}{|c|}{$\begin{array}{l}\text { Effect size } \\
1 \text { st to } 10 \text { th }^{\mathrm{a}}\end{array}$}} \\
\hline & \multirow[b]{2}{*}{ 1st } & \multirow[b]{2}{*}{ 10th } & \multirow[b]{2}{*}{ 1st } & \multirow[b]{2}{*}{ 10th } & \multirow{2}{*}{$\begin{array}{c}\text { p-value } \\
\text { 1st } \\
\end{array}$} & \multirow{2}{*}{$\begin{array}{c}\text { p-value } \\
\text { 10th }\end{array}$} & & & & \\
\hline & & & & & & & 1 st & 10th & Control & WAD \\
\hline SCM & $0.19(0.07)$ & $0.13(0.04)^{*}$ & $0.19(0.07)$ & $0.15(0.04)^{*}$ & 0.82 & 0.28 & 0.03 & 0.15 & 0.88 & 0.66 \\
\hline Lcap & $0.28(0.07)$ & $0.22(0.05)^{*}$ & $0.29(0.08)$ & $0.26(0.07)$ & 0.68 & 0.08 & 0.06 & 0.25 & 0.65 & 0.35 \\
\hline Lco & $0.30(0.08)$ & $0.24(0.07)^{*}$ & $0.33(0.10)$ & $0.29(0.09)$ & 0.22 & 0.03 & 0.18 & 0.31 & 0.62 & 0.30 \\
\hline
\end{tabular}

${ }^{\mathrm{a}}$ Effect size for the with-in group changes from the $1^{\text {st }}$ to $10^{\text {th }}$ arm elevation.

*Significant differences $(\mathrm{p}<0.05)$ between first and tenth arm elevations 


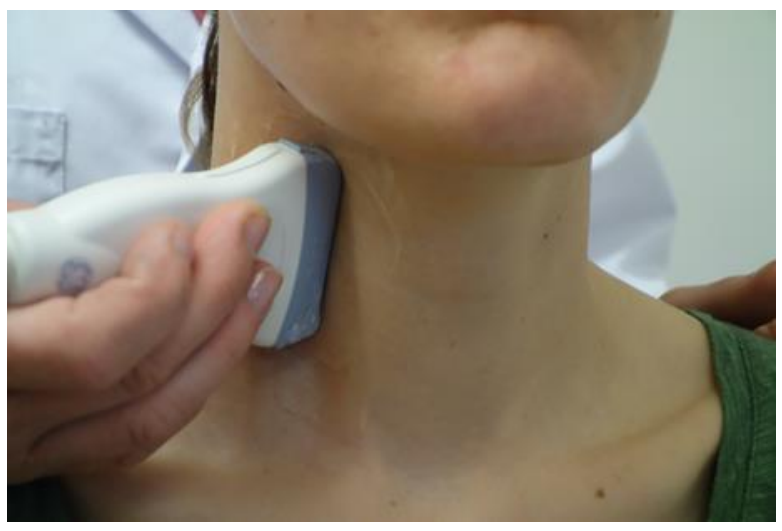

Fig. 1a. Position of the ultrasound probe.

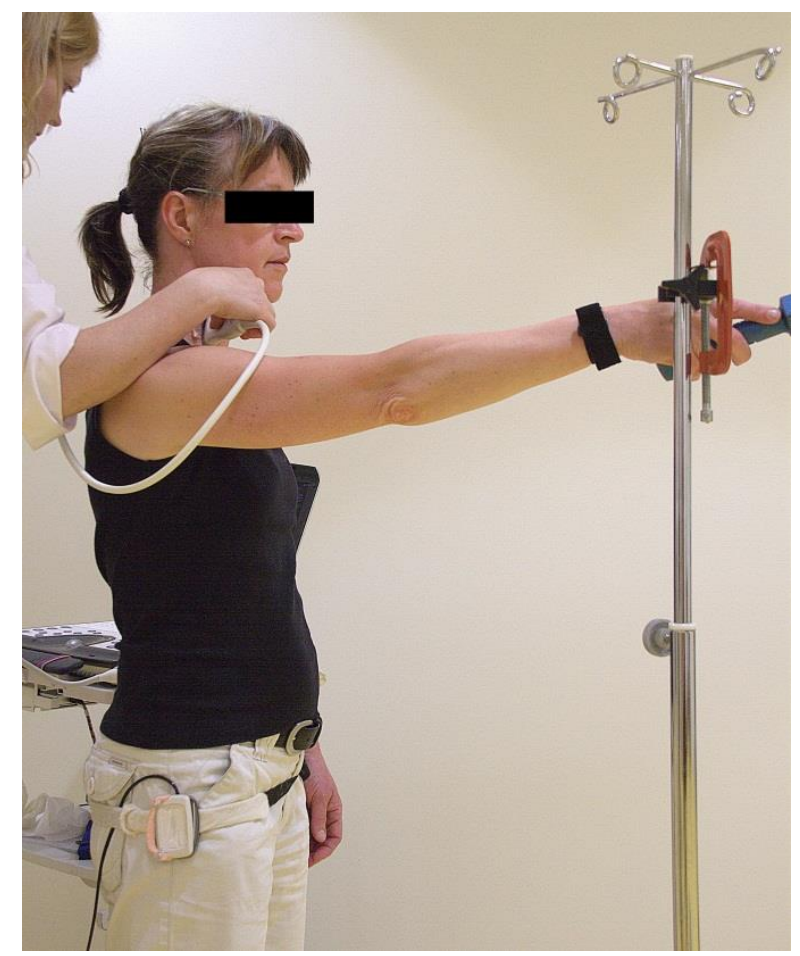

Fig. 1b. Ultrasound imaging of ventral neck muscles during arm elevation. The arm was raised to 90 degrees, and an adjustable horizontal bar was fixed with the index finger touching the bar. The subject held a weight of $0.5 \mathrm{~kg}$ (women) or $1 \mathrm{~kg}$ (men) in the right hand. A pair of customized contact switches was attached to the subject, one on the right wrist and one on the right hip. The contact signal was recorded in the ultrasound machine in the channel for the EKG system, to provide a cue for synchronizing data between the ultrasonograph and the starts and stops of arm movements.. A metronome was set at 40 beats per minute to maintain a steady pace during the examination. Each individual was asked to 
stand in an upright, comfortable position, with feet behind a line marked on the floor. The individual was then asked to hold the head steady, and when lifting the arm, to look at the bar, and try to keep pace with the metronome. With the beat, they should begin to raise the arm to the bar, and on the next beat, they should lower the arm to the switch contact with a smooth motion. The examiner, a manual therapist experienced in ultrasound recordings of the neck, held the probe. The other physiotherapist showed the participants how to perform the test and assisted the ultrasound examiner; for example, at the request of the examiner, the assistant might save the ultrasound imaging sequence in the ultrasound database. Thus, the physiotherapist holding the probe could concentrate on holding the probe in a stable position to capture clear images of the muscles of interest throughout the entire test.

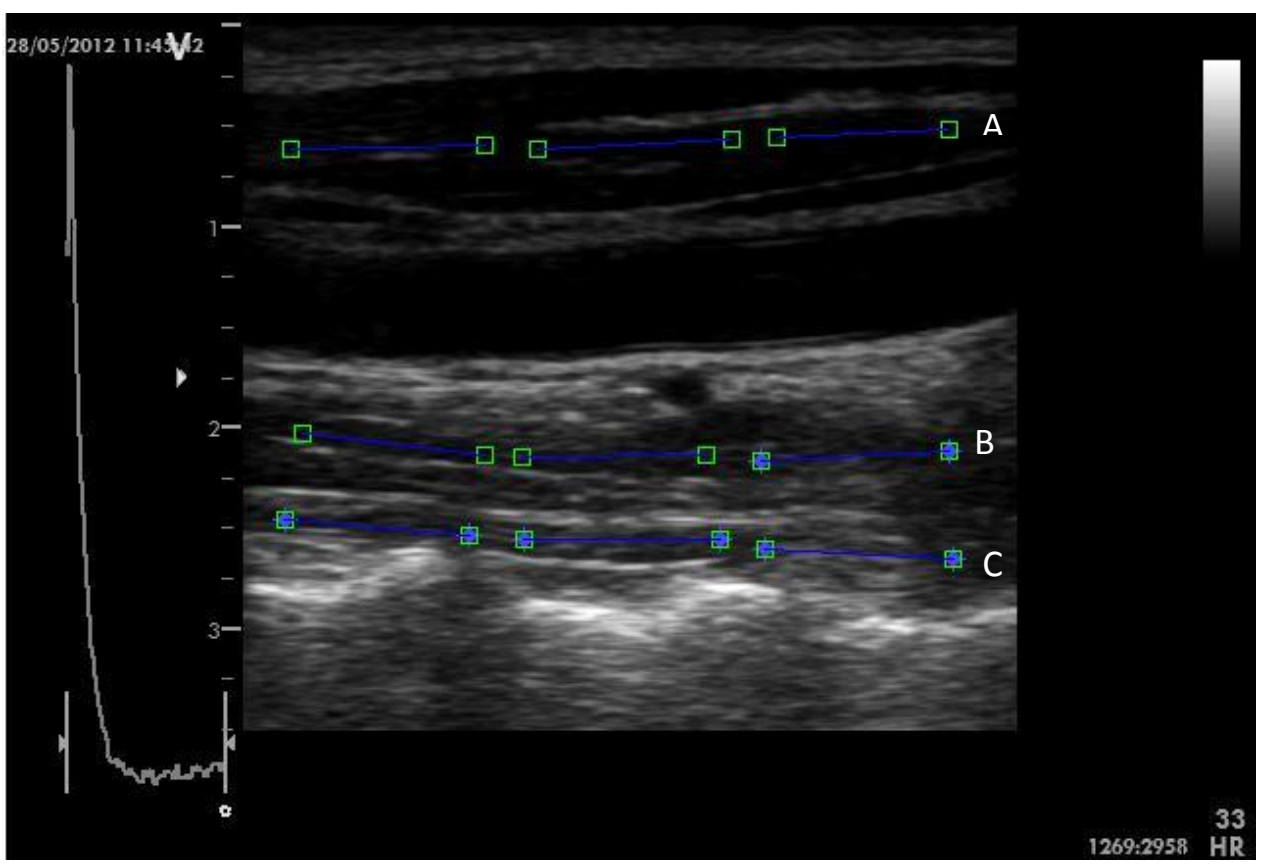

Fig. 2. An ultrasound image showing superficial and deep ventral neck muscles. Three regions of interest (ROIs; each indicated as a blue line with a square on each end) were 
selected in each muscle for post-process speckle tracking analysis. A = Sternocleidomastoid, $\mathrm{B}=$ Longus capitis, $\mathrm{C}=$ Longus colli.

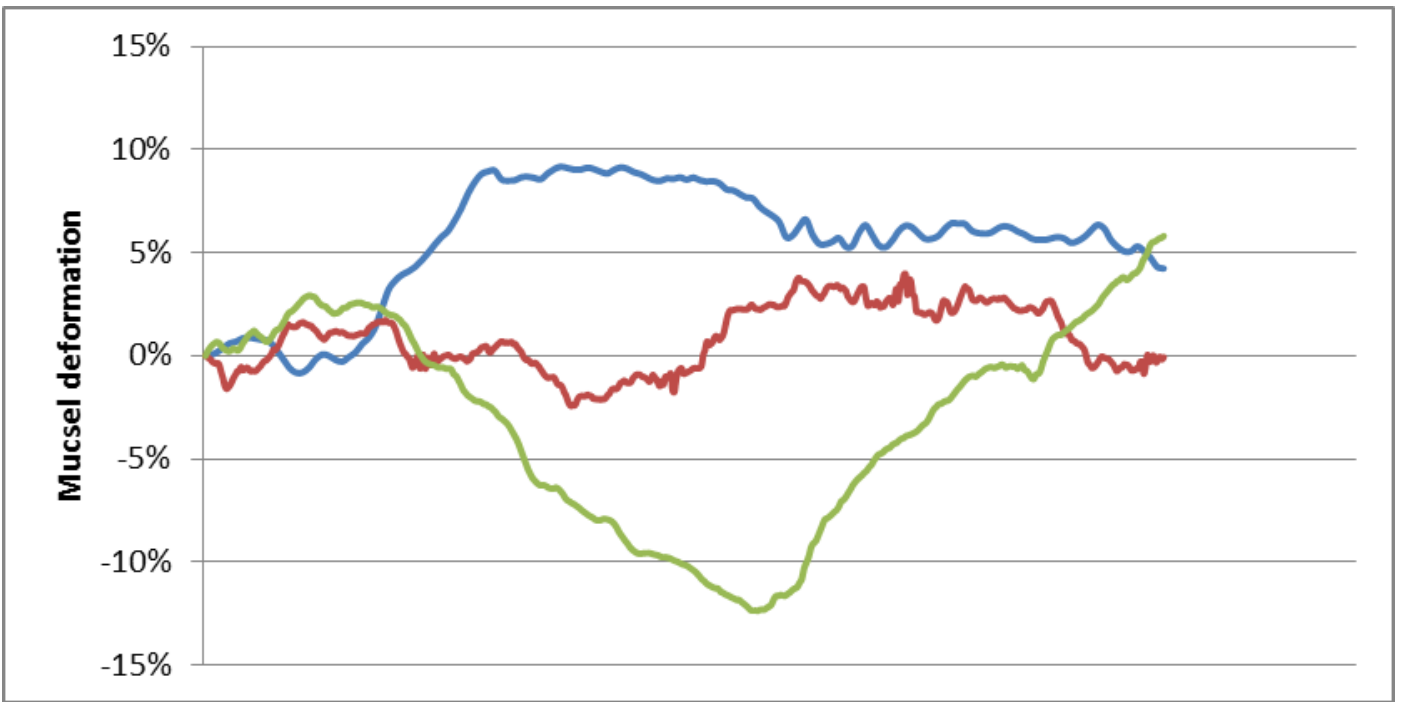

Fig. 3. Different muscle deformation sequences that can occur during one arm elevation. This diagram illustrates three different patterns of muscle deformations obtained for three different individuals (each line represents deformations in one individual). Each line represents the changes observed in the ROI (deformation \%) in one muscle, during one arm elevation. The region (area) below zero (negative values) represents muscle shortening and the region (area) above zero (positive values) represents muscle elongation. The total area (sum of negative and positive areas) represents the total muscle deformation during one arm elevation. When the line crosses the $0 \%$ line, the muscle switches from shortening to elongation, or vice versa. 


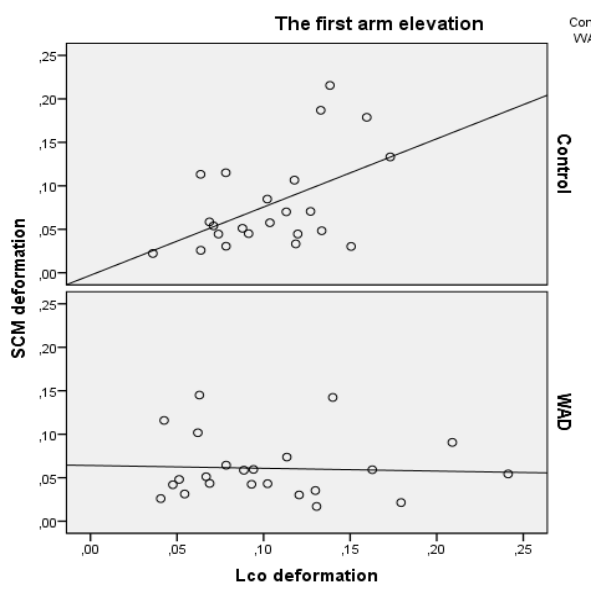

a)

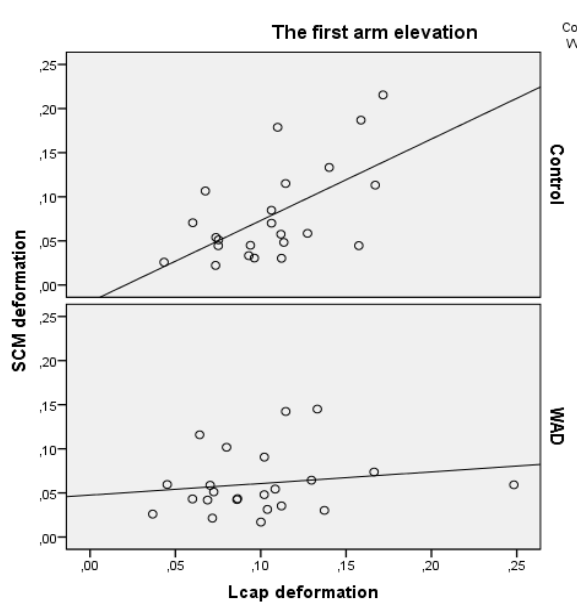

c)

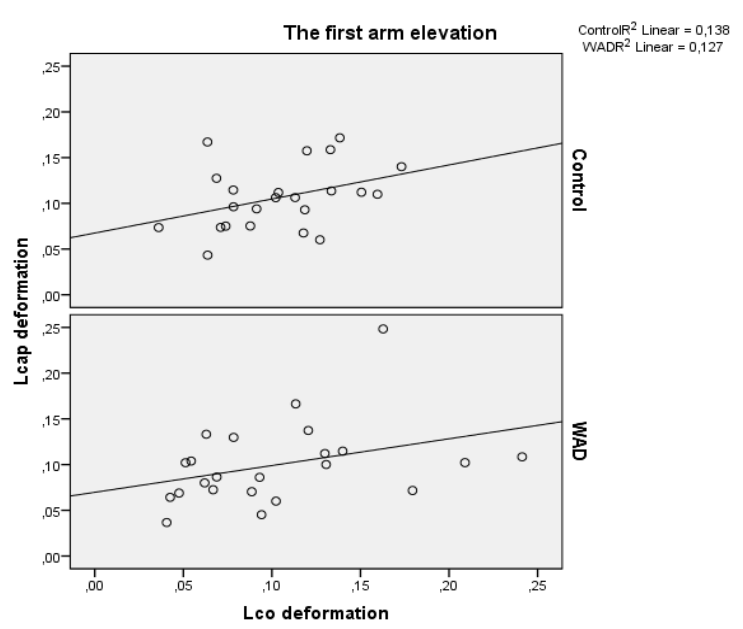

e)

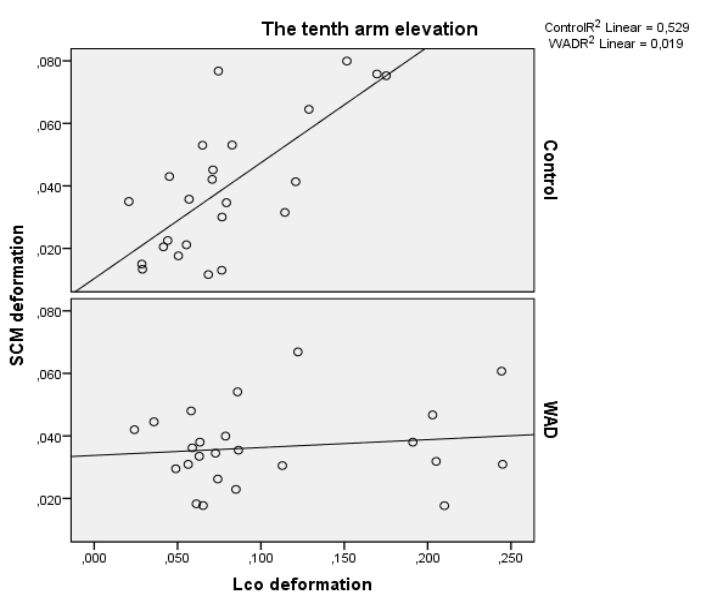

b)

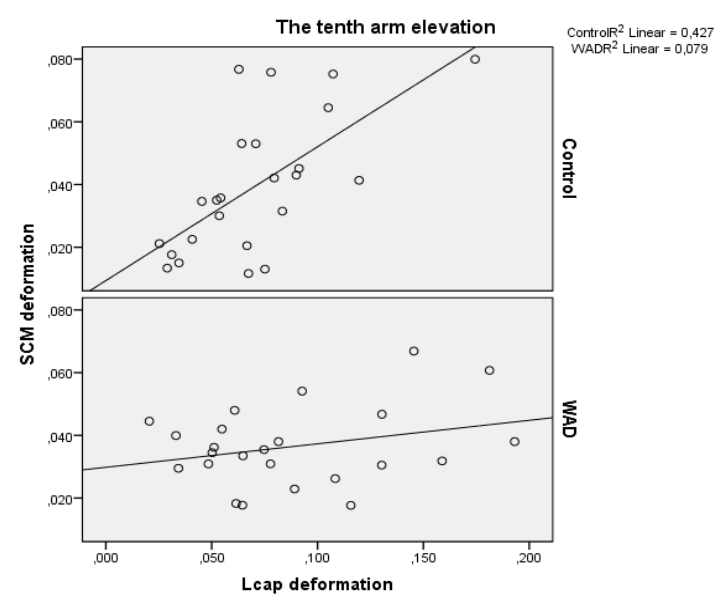

d)

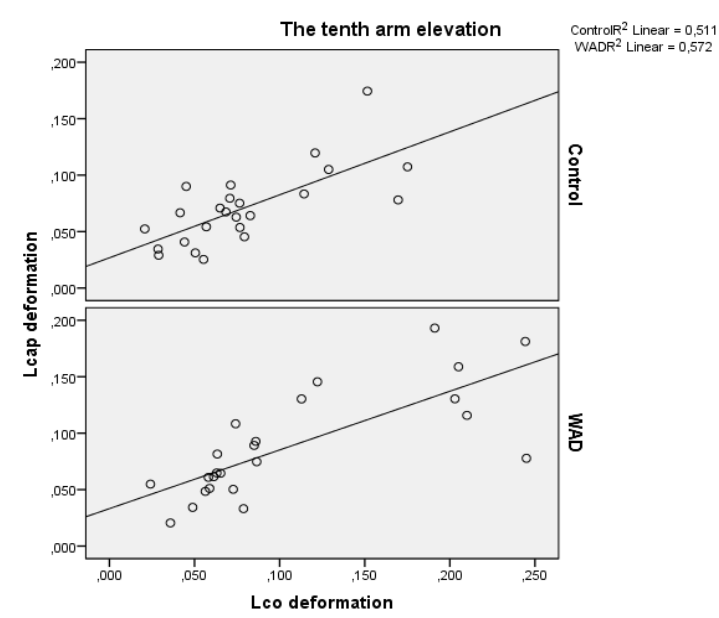

f) 
Fig. 4 a-f. Relationships between total deformation areas of muscle pairs. Linear relationships between muscle pairs are shown for the first and tenth arm elevations. (a,b) Relationships between sternocleidomastoid (SCM) and longus colli (Lco) muscles: (Top panels) Controls showed amoderate linear relationship during the 10th $\left(\mathrm{R}^{2}=0.53\right)$ arm elevations compared to the first (weak; $\mathrm{R}^{2}=0.25$ ); (bottom panels) individuals with WAD showed no linear relationships $\left(\mathrm{R}^{2}<0.02\right)$.

(c,d) Relationships between SCM and longus capitis (Lcap) muscles: (Top panels) Controls showed higher linear relationships (moderate) during the 10th $\left(\mathrm{R}^{2}=0.43\right)$ arm elevations compared to the first $\left(\mathrm{R}^{2}=0.35\right)$; (bottom panels) individuals with WAD showed no linear relationships $\left(\mathrm{R}^{2}=0.08\right.$ to 0.03$)$.

$(e, f)$ Relationships between Lcap and Lco: Both groups showed moderate linear relationships during the $10^{\text {th }}$ arm elevations compared to the weak linear relationship at the first arm elevations; (top panels) controls $\left(\mathrm{R}^{2}=0.14\right.$ to 0.51$)$; (bottom panels) individuals with WAD $\left(\mathrm{R}^{2}=0.13\right.$ to 0.57$)$. 


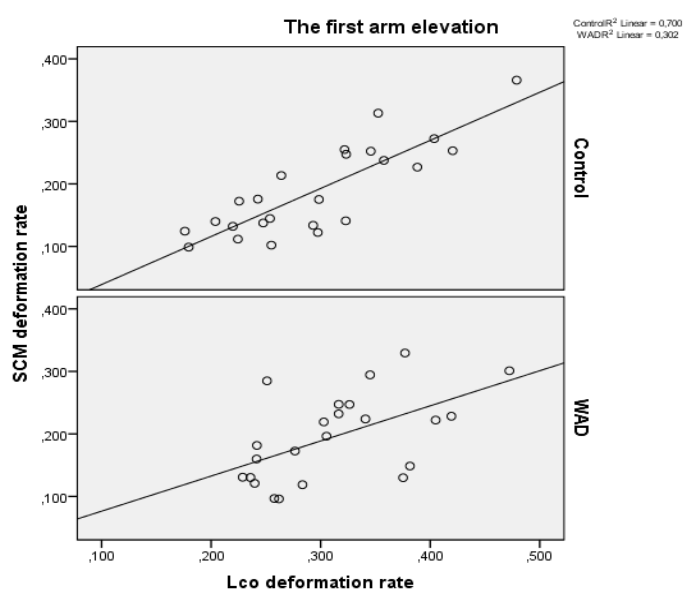

a)

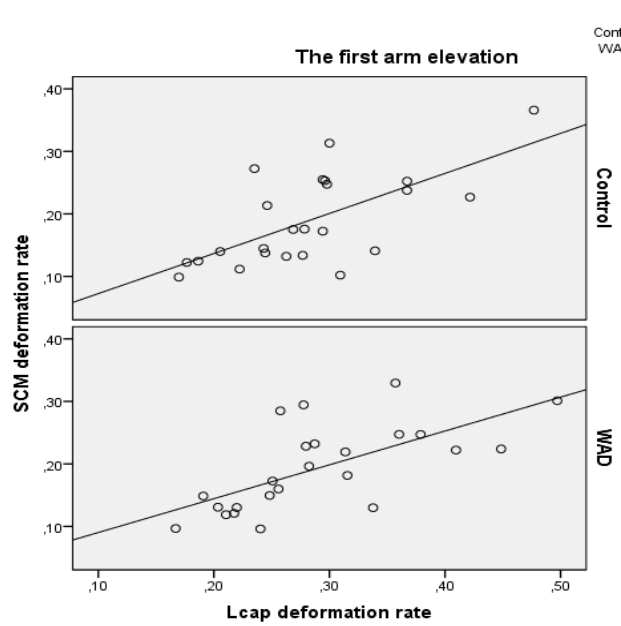

c)

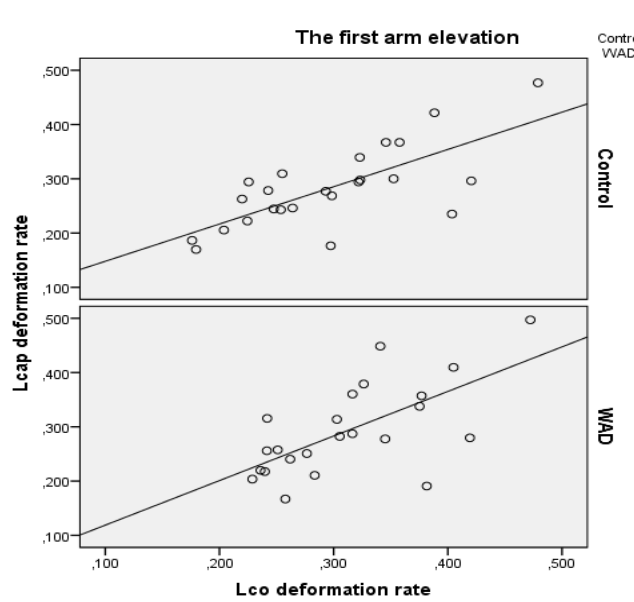

e)

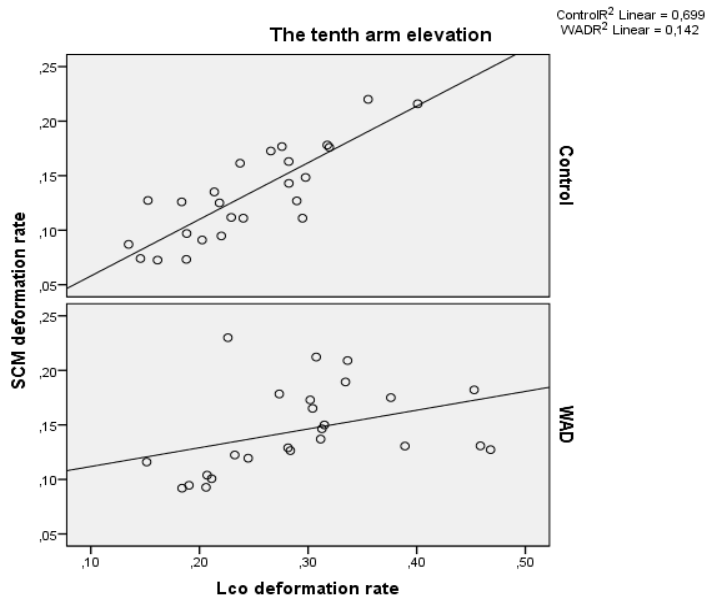

b)

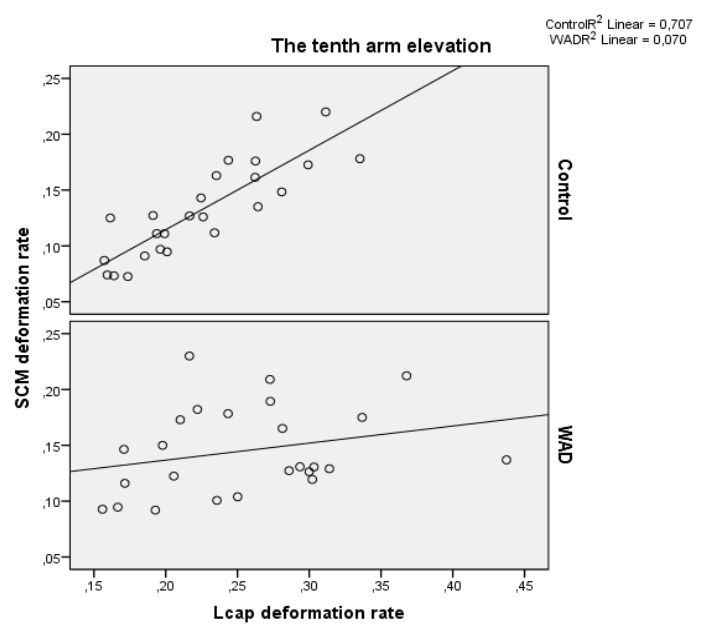

d)

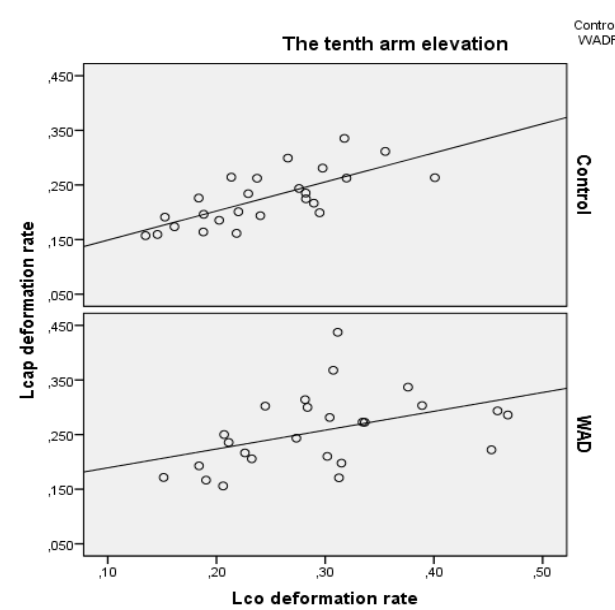

f) 
Fig. 5 a-f. Relationships between deformation rates of muscle pairs. Linear relationships between muscle pairs are shown for the first and tenth arm elevations.

(a,b) Relationships between sternocleidomastoid (SCM) and longus colli (Lco) muscles: (Top panels) Controls showed a strong linear relationship during both the 1st and the 10th arm elevations $\left(\mathrm{R}^{2}=0.70\right)$; (bottom panels) individuals with WAD showed a weak linear relationships during the tenth arm elevations $\left(\mathrm{R}^{2}=0.14\right)$ compared to the first (moderate; $\mathrm{R}^{2}=0.30$ ). (c,d) Relationships between SCM and Longus capitis (Lcap) muscles: (Top panels) Controls showed a strong linear relationship during the $10^{\text {th }}$ arm elevations $\left(\mathrm{R}^{2}=0.71\right)$ compared to the first (moderate; $\mathrm{R}^{2}=0.43$ ); (bottom panels) individuals with WAD showed a weak linear relationship during the 10 th arm elevations $\left(R^{2}=0.07\right)$ compared to the first (moderate; $R^{2}=$ $0.44)$.

(e,f) Relationships between Lcap and Lco muscles: (Top panels) controls showed equivalent linear relationships during the 1 st and 10th arm elevations (moderate; $\mathrm{R}^{2}=0.53$ ); (bottom panels) individuals with WAD showed a weak linear relationship during the $10^{\text {th }}$ arm elevations $\left(\mathrm{R}^{2}=\right.$ $0.19)$ compared to the first (moderate; $\mathrm{R}^{2}=0.43$ ). 